\title{
WEB-BASED IONIC LIQUIDS LEARNING MEDIA TO MEASURE THE COMPETENCE OF POLYTECHNIC STUDENTS
}

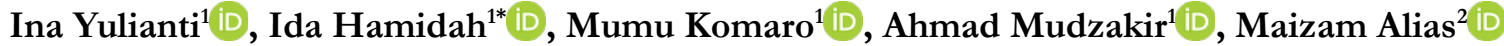 \\ ${ }^{1}$ Universitas Pendidikan Indonesia (Indonesia) \\ ${ }^{2}$ Universiti Tun Hussein Onn Malaysia (Malaysia) \\ yuliantiina@gmail.com, Corresponding author: idahamidab@upi.edu,mumukomaro@yahoo.com, \\ mudzakir.kimia@upi.edu,maizam58@gmail.com
}

Received November 2020

Accepted February 2021

\section{Abstract}

The rapid development of technology and information has influenced students' learning styles and has led to a shift in information seeking from printed books to e-books. This study aims to measure students' knowledge and skills, attitude, and website knowledge competency on the ionic liquid material. The study involved 47 students of the Diploma III Chemical Engineering program at a private polytechnic selected using a purposive sampling technique. This web-based Ionic Liquids learning was tested on students through the experiential learning model. Data collection was carried out by completing the competency test at the beginning (CT1) and the end of learning (CT2). The results revealed that website-based ionic liquid learning increased each competency of knowledge and skills of ionic liquids, knowledge of websites, and attitude. Even though not all students can do it independently, the learning could attract students' attention. The learning has to be combined with lecturers' explanations as reinforcing concepts. This research's implications are expected to be used as recommendations in enriching the Chemical Engineering education curriculum by adding website-based ionic liquid material.

Keywords - Education, experiential learning, ionic liquids, web-based learning.

\section{To cite this article:}

Yulianti, I., Hamidah, I., Komaro, M., Mudzakir, A., \& Alias, M. (2021). Web-based ionic liquids learning media to measure the competence of polytechnic students. Journal of Technology and Science Education, 11(2), 284-294. https://doi.org/10.3926/jotse.1145

\section{Introduction}

Technical and Vocational Education and Training (TVET) is one of Indonesia's educational institutions that prioritize acquiring knowledge and skills. To meet the demand for a skilled and independent workforce, TVET must collaborate with the industry to bridge the required skills. Oviawe (2017) suggests that TVET provides skills training to meet the workforce's needs in the $21^{\text {st }}$ century. The rapid globalization requires industrial workers in Indonesia to improve their work competence, following the standards set by the national standard called Indonesian National Work Competency Standards as the formulation of work capability standards that cover aspects of knowledge, skills, and work attitudes (Sánchez-García, Ureña-Molina, López-Medina \& Pancorbo-Hidalgo, 2019). Diploma students in the Chemical Engineering study program are prepared to acquire competencies stated in the national standard 
No. 165 of 2016, including competencies in planning, processing, and using chemicals for the production process in the face of competition in the global market. Chemical engineering students need insights and skills for selecting, processing, and using chemicals related to environmental safety.

Along with developing green material technology, it is necessary to introduce ionic liquid material as the latest chemical for various applications in the industrial field. The ionic liquid material is relatively new for polytechnic education. Thus it needs to be introduced, and for easy access to the material, the learning is presented in the form of a website (Kassinis \& Panayiotou, 2017).

Some studies have reported that the availability of educational resources on the web is an efficient way to obtain and share knowledge through e-Learning (Valenzuela, Fragoso, Santaolaya \& Munoz, 2017). The study in the application of ionic liquids in industries, especially chemical engineering, found that the room temperature petrochemical industry of ionic liquids (RTIL) was introduced as a new solvent for separating various gases hydrocarbons (Palgunadi, Indarto, Winoto \& Kim, 2010). However, the reality shows no polytechnic education in Indonesia includes this ionic liquid material in the curriculum. In the present study, the innovation of ionic liquid material in this web design is the SINUS menu (Interactive Simulation of ion Liquids-Sketch), used in learning. The learning using SINUS is expected to enhance students' competence, skills, and attitudes in designing ionic liquids. Using simulations for making imidazolium salt structures as an example of ionic liquids and making a graph to predict the type of ionic liquid, also one of the innovations in this SINUS. Related to this, learning ionic liquids is considered very urgent to be given to polytechnic students to increase competence in planning, processing, and using chemicals that are safe for the production process.

\section{Literature Review}

\subsection{Web-Based Learning}

Web-based learning refers to online learning or e-learning. Discussion forums via email, video conferencing, and live lectures (video streaming) are all possible via the web. Web-based learning, known as web-based training (WBT) or web-based education (WBE), can be defined as a web technology application for the educational process (Rusman, 2016). It offers unlimited speed in space and time in accessing information. Students can easily carry out learning activities as long as a computer or smartphone is connected to the internet network. A website is a collection of pages with specific content and purpose, and users can access the website with several devices such as laptops, desktops, smartphones, or tablets. The main requirement for learning through the web is access to information sources. Some data sources can be accessed freely without administrative processes, while others can only be accessed by parties that have been authorized by the owner of the source of information. One source of data that has been developed and can be accessed by users for learning is the website http://mopekimia.gamma.co.id as can be seen in Figure 1. The authors developed this website to facilitate students in learning ionic liquids.

The web was designed for teaching materials, including ionic liquid material, learning videos, interactive simulations, student evaluations, questionnaires, and a recap of exam results. All of them are summarized in the website features of the main home page menu, material, experiment guidance (LKI), interactive simulation ionic liquids sketch (SINUS), learning video, evaluation, and exam results. Students can choose the menu according to their needs by clicking the menu and sub-menu available. Some initial information is provided on the home page menu, such as learning objectives, general web usage guidelines, and an explanation of each menu and sub-menu. The material menu contains preliminary, science, engineering, and ionic liquid technology sub-menus. The introductory sub-menu includes the definition and history of ionic liquids. The science sub-menu includes basic structure, encoding, imidazolium molecular structure, physical-chemical properties, and melting point. The engineering sub-menu includes the effect of ion size on the melting point of the imidazolium ion liquid, the effect of the alkyl chain, and the size of the anion on the melting point ionimidazolium liquid, synthesis, quaternization reaction, and metathesis reaction. The technology sub-menu includes applications, ionic liquids, and green chemistry, enhancing the sustainability of ionic liquids, and ionic innovation in chemical engineering. 


\section{Sains, Rekayasa dan Teknologi Cairan Ion}

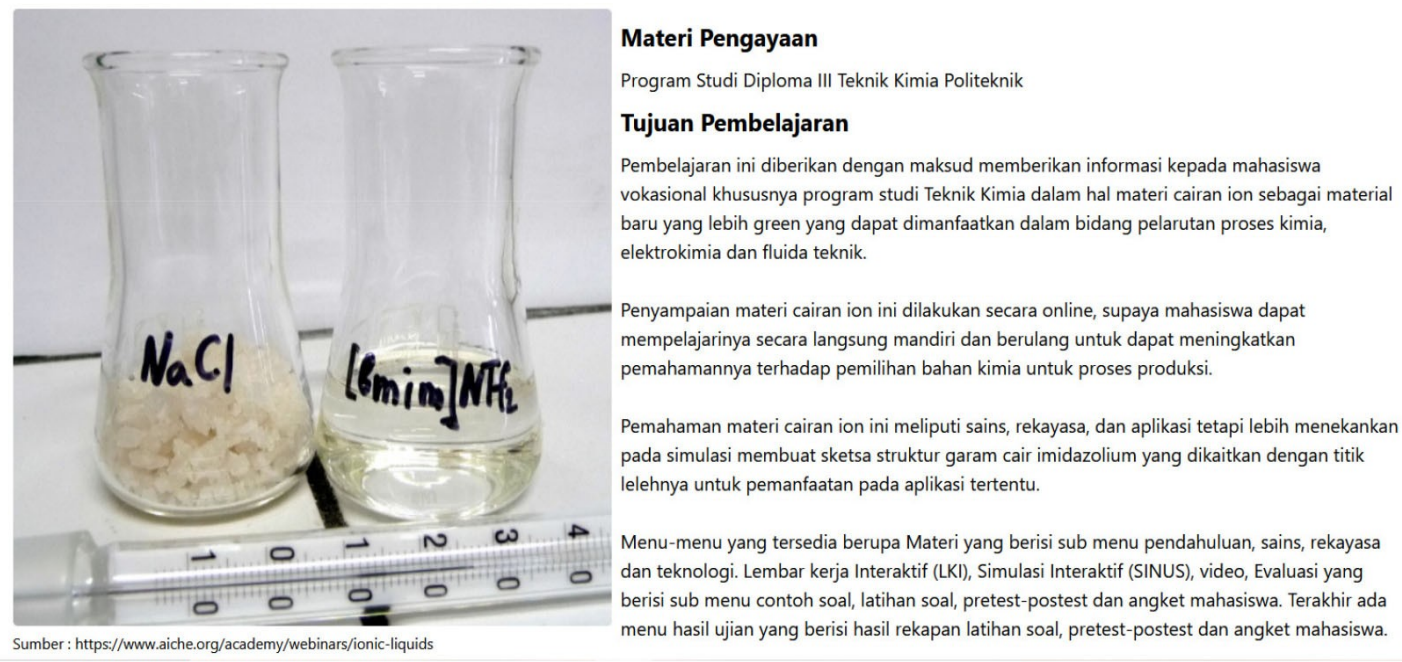

Figure 1. Web-based ionic liquids learning design (http://mopekimia.gamma.co.id)

The LKI menu is an interactive worksheet in the form of interactive practical procedures on the effect of changes in the length of the alkyl chain on the cation and type of anion (anion size) imidazolium ionic liquid on its salt melting point in a simulated form. It contains objectives, theoretical basis, work steps, and questions that students must answer after completing the simulation. Meanwhile, SINUS is an exercise in designing the structure of an imidazole liquid in the form of a salt with cationic imidazole and various anions such as $\mathrm{Cl}-, \mathrm{Br}-, \mathrm{PF} 6-, \mathrm{BF} 4-$, TfO-, and TFSI-. Structural design is done according to the procedures in the LKI. Based on the structure, students can determine the value of the melting point and graph the relationship between the structure of the ionic liquid and its melting point by clicking on the available show chart, as shown in Figure 2.

By extrapolating the graph as shown in Figure 3, students can determine the type of ionic liquid used at room temperature or below room temperature. This information is essential for chemical engineering students to plan, prepare, and use chemicals that are safe for industrial processes.

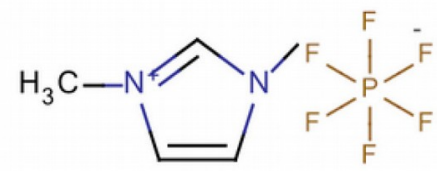

Kombinasi : $\mathrm{C} 1+\mathrm{M} 1+\mathrm{PF} 6$

Melting point prediksi : $126.3^{\circ} \mathrm{C}$

Melting point observasi : $130^{\circ} \mathrm{C}$

Figure 2. Designing an ionic liquid structure

The video menu includes a science video describing ionic liquids as low-melting ionic salts, engineering videos explaining the structure and properties of ionic liquids, and ionic liquids technology videos, including applications on batteries. Meanwhile, the evaluation menu contains sample questions, practice exercises, competency tests in the form of pre-test and post-test, and student questionnaire attachments. 
Exam results include the results of the practice questions and student questionnaires. To enter the evaluation menu, special access is required where students must log in and register first with the link address http://mopekimia.gamma.co.id/registration/ to facilitate the recording of test results. Web-based learning has been useful for some reasons: as it can connect information sources in a variety of different formats; can be an efficient way of delivering subject matter, information sources can be provided from any location and at any time; can be potential to expand access; can encourage more independent and active learning; and can provide a useful source of complementary materials for conventional programs (Safitri, Hamidah \& Setiawan, 2019).

The web also contains hyperlinks that connect to other parts of the web and allow access to large amounts of information. With web-based learning, the material can be linked to libraries (for example, for ordering books or journals), online databases, and electronic journals. However, web-based design learning has some disadvantages. Students feel frustrated if they cannot access graphics, images, and video clips because of the lack of facilities. Besides, the required infrastructure must be available and affordable. As information can vary in quality and accuracy, guidance is needed, and students can feel isolated from the outside world. Web-based learning in an institution is often integrated with conventional face-to-face teaching. It is usually done via an intranet, usually "password protected," and can only be accessed by registered users. Thus, it is possible to protect the intellectual property of online material and support the exchange of confidential communications between students (Graham, 2019).

\section{Chart Melting Point}

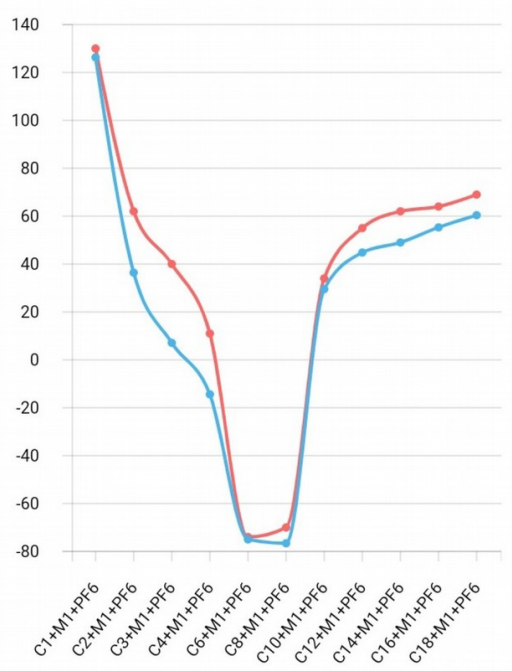

Figure 3. Graph of the effect of the alkyl chain on the melting point

\subsection{Experiential Learning Theory}

The Experiential Learning Theory (ELT) model has been conceptualized as a process that involves students in an iterative cycle based on reflection, generation of theories, and application of knowledge (experiments), which results from real experiences (Kolb, 1984). Kolb's model consists of concrete experiences, reflective observations, abstract conceptualizations, and active experiments (see Figure 4). In this model, students follow the learning stages, like experiencing, reflecting, thinking, and acting in a recursive process sensitive to the learning situation and what is being learned. Concrete experiences directly expose the subject, evoking initial reactions, intuitive impressions, and affective responses. During a reflective observation, students make meaning from the observation experience and interpretation of events. Students also work in groups to discuss, share, and exchange ideas to get more in-depth observations (Gillies, 2019). 


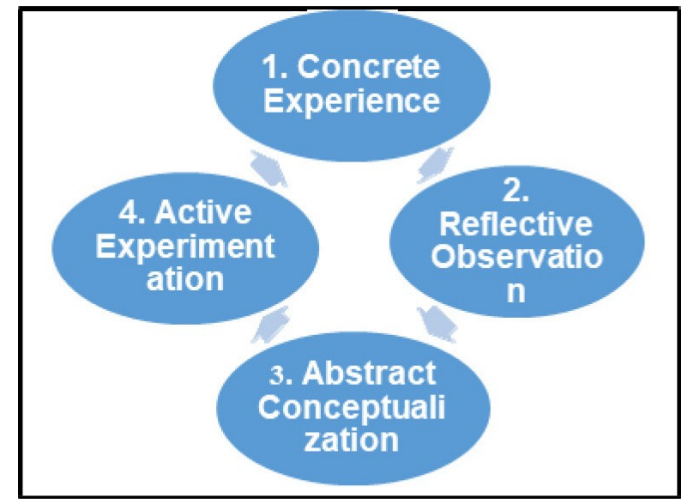

Figure 4. Adoption Experience Learning Cycle

Students form theories based on interpretations of the observed events during the abstract conceptualization, which can be linked to existing ideas or new ideas. In the final stage of an active experiment, students test the emerging theories. This stage serves as a guide in creating new experiences and can act as a basis for confirming or modifying emerging theoretical understandings. Kolb's model provides valuable experience for learning about how students build an understanding of ionic liquids from observing events in web-based learning and from interpretations of their actions. Active experience activities through interactive simulations SINUS can help students be more creative without memorizing content (Tong, Loc, Uyen \& Cuong, 2020).

\subsection{Ionic Liquid}

Ionic liquids are salts liquid with melting points below $100{ }^{\circ} \mathrm{C}$, even below room temperature (Berthod, Ruiz-Ángel \& Carda-Broch, 2018). Ionic liquids consist of large and asymmetrical organic cations, derived from imidazolium, pyridinium, pyrrolidinium, ammonium, phosphonium, and sulfonium. Common anions include halides, tetrachloroaluminate, hexafluorophosphate, tetrafluoroborate, and bis (trifluoromethylsulfonyl) imide-inorganic and organic anions such as alkylsulfate, alkylsulfonates, p-toluenasulfonates (tosylates), and trifluoroacetates. Examples of ionic liquid salts with imidazolium cations are (a) 1.3 dimethyl imidazolium hexafluoropospate and (b) 1.3 dimethyl imidazolium tetrafluroborate, as shown in Fiure 5.

Ionic liquids have characteristics that make them preferred over traditionally available solvents. The characteristics include solvating ability, no/little vapor pressure, non-flammable, high thermal and electrochemical stability, extensive liquid range, ease to recycle, very polar, chiral, long shelf life, and conductivity (Irge, 2016).

The properties of ionic liquids depend on the cations and their constituent anions. It provides great potential in designing ionic liquids for a variety of applications (Vekariya, 2017). The provision of solvent media for environmentally friendly chemical reactions is the latest effort to replace traditional solvents. The availability of ionic liquids that are easy, non-toxic, non-flammable, and environmentally friendly is an irreplaceable benefit by other types of solvents (Mannekote, Kailas, Venkatesh \& Kathyayini, 2018).

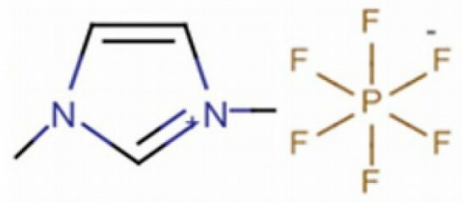

(a)

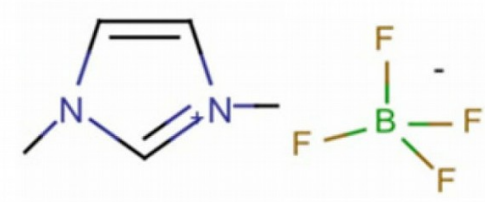

(b)

Figure 5. Ionic liquid salts with imidazolium cations 
Examples of ionic liquids are volatile, flammable, and toxic organic solvents, while ionic liquids are green solvents (Khandelwal, Tailor \& Kumar, 2016). Ionic liquids are introduced as green materials to minimize environmental pollution from solvents that endanger the environment.

\section{Methodology}

\subsection{Research Goal}

Web-based ionic liquid learning material was developed with the 4D model through the stages of definition, design, development, and dissemination (Thiagarajan, 1974). This research aims to measure the competence of students on website-based ionic liquid material, including ionic liquid knowledge and skills, attitude, and website knowledge. Students' competence was measured after the implementation of web-based ionic liquid teaching materials using experiential learning theory (ELT). Our previous study shows that the lecturers' interest and willingness to explore and disseminate ionic liquid material is very high. On the other hand, the level of student understanding of ionic liquids is still low and needs improvement. For this reason, it is necessary to design an Ionic Liquid teaching material that is attractive to study and easy to understand by both lecturers and students (Yulianti, Hamidah \& Komaro, 2020).

\subsection{Sample and Data Collection}

This study involved 47 students of the Diploma III Chemical Engineering program at a private polytechnic in Bandung Indonesia who were selected using a purposive sampling technique (Etikan, 2016). The quantitative data were collected through competency tests (Carpino, Mora \& Simone, 2019). The competency test had three parts. Part A collects information data about aspects of ionic liquid knowledge and skills (10 items), Part B collects data aspects of website knowledge (5 items), and Part C collects data aspects of attitude (5 items). Each item is measured using a 5-point Likert scale from 1 Strongly Disagree to 5 Strongly Agree.

Before the research was conducted, the participating students worked on an initial competency test (CT1). Then, they were given some problems to find out the solutions (problem-solving). For example, are there any greener chemicals used in chemical processes that are liquid at room temperature? Next, based on the Learning Experience cycle stage (Kolb, 1984), the students applied is the concrete experience. Students opened the website http://mopekimia.gamma.co.id, and reviewed the articles and videos on ionic liquid material on the website. The second stage is reflective observation, where students reflected on what was studied in the article. For this stage, students could discuss with other students to get more extensive information about ionic liquids. The third stage was the abstract conception, where students generalized new theories due to the reflection stage. The new theories could be implemented in the fourth stage, the active experiment stage. At this stage, students carried out the interactive simulation and found solutions to problems presented based on the theories obtained from this experience. This research took place in one cycle. However, if the students need to verify the new findings, the next cycle of the research could be performed. At the end of the activity, students filled out the final competency test (CT2).

\section{Results and Discussion}

\subsection{Result}

The competency data analysis for indicators of knowledge, skills, and attitudes was divided into three categories: the difference in scores between CT2 and CT1. The positive category means the positive difference in scores means indicating an increase in competency. The fixed category means no increase/decrease in score. Meanwhile, the harmful category is indicated by a negative score of the difference, showing a decrease in competency (see Tables 1 to 3 ).

Table 1 shows that the average difference score of knowledge and skills of ionic liquids is $10.7 \%$, indicating that overall, the student knowledge and skills of ionic liquids increased. 


\begin{tabular}{|l|r|r|r|}
\hline Knowledge and skills of ionic liquids & $\begin{array}{c}\text { CT1 score, } \\
\text { \% }\end{array}$ & \multicolumn{1}{c|}{$\begin{array}{c}\text { CT score, } \\
\text { \% }\end{array}$} & \multicolumn{1}{|c|}{$\begin{array}{c}\text { The difference } \\
\text { score, } \%\end{array}$} \\
\hline Ionic liquids are ionic salts & 81.7 & 84.3 & 2.6 \\
\hline Ionic liquids can be liquid at room temperature & 81.7 & 91.9 & 10.2 \\
\hline Ionic liquids are green material & 68.9 & 90.6 & 21.7 \\
\hline One of the properties of ionic liquids is the low vapor pressure & 68.5 & 72.3 & 3.8 \\
\hline $\begin{array}{l}\text { Ionic liquids can be designed and can be synthesized for certain } \\
\text { applications }\end{array}$ & 74.9 & 85.1 & 10.2 \\
\hline Ionic liquids are electrolytes & 82.1 & 94.5 & 12.3 \\
\hline Ionic liquids contain no solvents & 61.7 & 77.4 & 15.7 \\
\hline Ionic liquids can replace ionic salts with high melting points (Tm) & 71.5 & 83.0 & 11.5 \\
\hline $\begin{array}{l}\text { Ionic liquids generally consist of organic cations with } \\
\text { organic/inorganic anions }\end{array}$ & 77.0 & 80.4 & 3.4 \\
\hline $\begin{array}{l}\text { Because of their unique properties, ionic liquids can be used for many } \\
\text { applications }\end{array}$ & 76.2 & 91.5 & 15.3 \\
\hline Average & $\mathbf{7 4 . 4}$ & $\mathbf{8 5 . 1}$ & $\mathbf{1 0 . 7}$ \\
\hline Standard deviation & $\mathbf{6 . 8}$ & $\mathbf{7 . 1}$ & \\
\hline
\end{tabular}

Table 1. The scores of knowledge and skills of ionic liquids

\begin{tabular}{|l|r|r|r|}
\hline Knowledge of website & $\begin{array}{c}\text { CT1 score, } \\
\mathbf{\%}\end{array}$ & $\begin{array}{c}\text { CT2 score, } \\
\text { \% }\end{array}$ & $\begin{array}{c}\text { The difference } \\
\text { score, \% }\end{array}$ \\
\hline The existence of a website is beneficial in understanding material & 88.5 & 89.4 & 0.9 \\
\hline Web-based learning is very profitable & 79.1 & 85.5 & 6.4 \\
\hline $\begin{array}{l}\text { The web can contain videos, articles, worksheets, animations, and } \\
\text { quizzes }\end{array}$ & 90.6 & 91.1 & 0.4 \\
\hline Web-based learning is not limited by space and time & 77.0 & 81.3 & 1.3 \\
\hline $\begin{array}{l}\text { In web-based learning, there is an interaction between students and } \\
\text { teachers }\end{array}$ & $\mathbf{8 4 . 3}$ & $\mathbf{8 6 . 9}$ & 4.3 \\
\hline Average & $\mathbf{5 . 9}$ & $\mathbf{3 . 8}$ & $\mathbf{2 . 6}$ \\
\hline Standard deviation & & \\
\hline
\end{tabular}

Table 2. The scores of knowledge of website

Table 2 shows the scores of student knowledge level on the website. The overall score shows that there is an increase in understanding of the website.

Table 3 shows the scores on the aspect of attitude. The overall difference score was positive, indicating an increase in student attitude towards web-based learning. The students found that the web-based learning on ionic liquid increased their interest and willingness to learn more on the topic. If students can improve their competence in ionic liquids, they understand that non-volatile and non-flammable chemicals do not pollute the environment (Montalbán, Víllora \& Licence, 2018).

Overall, ionic liquid website media can increase students' knowledge, skills, and attitudes. Unlike other aspects, in the aspect of knowledge and skills of ionic liquids, the standard deviation of CT2 is more significant than CT1. These results indicate that the pre-test score is closer to the mean grade compared to the post-test. However, we can still find that the standard deviation is small for all aspects, and it shows a small variation of each CT score to the mean grade.

The data (knowledge and skills of ionic liquids, knowledge of website, and attitudes) are normally distributed with a 95\% Confidence Interval. The paired t-test was carried out to detect a significant difference between the CT1 and CT2. For the knowledge and skills of ionic liquids and attitudes, there was a significant difference between CT1 and CT2, but there is no significant difference between CT1 and CT2 for the website's knowledge. 


\begin{tabular}{|l|r|r|r|}
\hline Attitude & $\begin{array}{r}\text { CT1 score, } \\
\text { \% }\end{array}$ & $\begin{array}{r}\text { CT2 score, } \\
\text { \% }\end{array}$ & $\begin{array}{c}\text { The difference } \\
\text { score, } \mathbf{\%}\end{array}$ \\
\hline I am very interested in web-based learning. & 73.2 & 80.0 & 6.8 \\
\hline Ionic liquids learning is needed in polytechnics as enrichment material & 80.4 & 87.7 & 7.2 \\
\hline I always look for solutions in doing my tasks with the help of the web & 84.3 & 86.8 & 2.6 \\
\hline I am interested in new material ionic liquids & 80.0 & 86.8 & 6.8 \\
\hline $\begin{array}{l}\text { I am willing to learn and implement this knowledge of ionic liquids in } \\
\text { the planning, selection, and use of chemicals in the production } \\
\text { process }\end{array}$ & 83.4 & 85.5 & 2.1 \\
\hline Average & $\mathbf{8 0 . 3}$ & $\mathbf{8 5 . 4}$ & \\
\hline Standard deviation & $\mathbf{4 . 4}$ & $\mathbf{3 . 1}$ & $\mathbf{5 . 1}$ \\
\hline
\end{tabular}

Table 3. The scores of attitudes

\subsection{Discussion}

Based on the results, there is an increase in the average score for the three aspects: knowledge and skills of ionic liquid, website knowledge, and student attitudes towards website use. The average score of all three aspects was positive. For the aspect of knowledge and skills of ionic fluids (see Table 1), the average score of before learning web-based learning (CT1) was $74.4 \%$, and that of after learning (CT2) was $85.1 \%$. It indicates an increase in student understanding by $10.7 \%$. The highest score is achieved on indicator Ionic liquids are green material, 20, which shows that students have a new understanding of ionic liquids as an environtmentally friendly green material (Mannekote et al 2018). For the knowledge of the website (see Table 2), there is an increase from CT1 to CT2 of 2.6\%. The paired t-test carried out that there is no significant difference in increasing CT1 to CT2. It means that students have good competence in using the website before learning (Rusman, 2016). Meanwhile, for the student's website knowledge, the average score for CT1 $=80.3 \%$ and CT2 $=85.4 \%$ with an increase of $5.1 \%$. These results indicate students' interest and desire to be able to apply knowledge of web-based ionic liquids in the selection and processing of chemicals and the synthesis and production of chemicals.

Based on some of the respondents' opinions about learning of web-based ionic liquids and the results of competency test data processing, four things become priorities - first, the concept of ionic liquids as green materials and electrolytes. Chemical engineering students need mastery of this concept in choosing chemicals as green solvents (Raj, Magaret, Pranesh, Lethesh, Devi \& Mutalib, 2019) that do not evaporate and do not pollute the environment. Second, the structure of ionic liquids is very different from ionic salts with high melting points. In ionic salts, the electrostatic attraction between cations and anions is powerful, producing a powerful bond with a dense and regular crystal structure. Whereas in ionic liquids, the electrostatic force is fragile because the cation size is greater than the relatively small anion size so that it becomes asymmetrical, and the distance between the ions becomes more tenuous so that it can form a liquid phase at room temperature (Wang, Sarman, Laaksonen, Golets, Mocci \& Lu, 2019). This liquid ionic liquid phase is efficient in the industry compared to ordinary ionic salts that are solid at room temperature. Third, in web-based learning, there are interactions between students and lecturers. Apart from the fact that only the interaction between students and computers, students can interact directly with the lecturer via the web. Fourth, learning with the web, of course, is very helpful for every lecturer and student in finding more detailed and precise information in a shorter time, because, with the website, we can explore the world of information widely, unobstructed by space, and time (Nicolaescu, Rosenstengel, Derntl, Klamma \& Jarke, 2018). Finally, with website-based learning, lecturers can design and elaborate learning content with various modes of representation. The variety of representation modes in this learning content are real, can enrich knowledge insights, and increase student understanding of the material (Zakiya, Sinaga \& Hamidah, 2017; Taher, Hamidah, Suwarma, 2017). Other studies also demonstrated that a weblearning environment affected enhancing learning motivation (Sekine, 2020). 


\section{Conclusions}

Polytechnic students' competence in learning web-based ionic liquids shows an increase in each aspect of ionic liquids' knowledge and skills, knowledge of websites, and attitude. However, the increase has not reached the maximum. Learning cannot be done. Personally, it must still be combined with lecturers' explanations as reinforcing concepts through face-to-face meetings in the classroom, especially for concepts that are difficult to understand, such as the structure and physical-chemical properties of ionic liquids.

An increase in the three aspects' competence shows that learning through web-based ionic liquids can be used as a reference for the development of the curriculum. New knowledge of ionic liquids can be used as a reference in choosing green chemicals to improve work competence in planning, processing, and using chemicals in the production process. Ionic liquids as greener solvents should be socialized to students to be used in practicum and research as a substitute for organic solvents that are volatile and flammable.

\section{Declaration of Conflicting Interests}

The authors declared no potential conflicts of interest with respect to the research, authorship, and/or publication of this article.

\section{Funding}

The authors would like to thank the Ministry of Education and Culture Republic of Indonesia for funding of Doctoral Dissertation Grant with 16/EI/KPT/2020.

\section{References}

Berthod, A., Ruiz-Ángel, M.J., \& Carda-Broch, S. (2018). Recent advances on ionic liquid uses in separation techniques. Journal of Chromatography A, 1559, 2-16.

https://doi.org/10.1016/j.chroma.2017.09.044

Carpino, C., Mora, D., \& Simone, M. De. (2019). On the use of questionnaire in residential buildings. A review of collected data, methodologies and objectives. Energy and Buildings, 186, 297-318.

https://doi.org/10.1016/j.enbuild.2018.12.021

Etikan, I. (2016). Comparison of Convenience Sampling and Purposive Sampling. American Journal of Theoretical and Applied Statistics, 5(1), 1-4. https://doi.org/10.11648/j.jajtas.20160501.11

Gillies, R.M. (2019). Promoting academically productive student dialogue during collaborative learning. International Journal of Educational Research, 97, 200-209. https://doi.org/10.1016/j.ijer.2017.07.014

Graham, N.V. (2019). A qualitative multiple case study of factors that impact educator's success in an online environment. Available at: https://eric.ed.gov/?id=ED590780

Irge, D.D. (2016). Ionic Liquids: A Review on Greener Chemistry Applications, Quality Ionic Liquid Synthesis and Economical Viability in a Chemical Processes. American Journal of Physical Chemistry, 593, 74-79. https://doi.org/10.11648/j.ajpc.20160503.14

Kassinis, G., \& Panayiotou, A. (2017). Website stories in times of distress. Management Learning, 48(4) 1-19. https://doi.org/10.1177/1350507617690684

Khandelwal, S., Tailor, Y.K., \& Kumar, M. (2016). Deep eutectic solvents (DESs) as eco-friendly and sustainable solvent/catalyst systems in organic transformations. Journal of Molecular Liquids, 215, 345-386. https://doi.org/10.1016/j.molliq.2015.12.015

Kolb, D.A. (1984). Experiential learning: Experience as the source of learning and development. New York: Prentice-Hall International. 
Mannekote, J.K., Kailas, S.V., Venkatesh, K., \& Kathyayini, N. (2018). Environmentally friendly functional fluids from renewable and sustainable sources-A review. Renewable and Sustainable Energy Reviews, 81(2), 1787-1801. https://doi.org/10.1016/j.rser.2017.05.274

Montalbán, M.G., Víllora, G., \& Licence, P. (2018). Ecotoxicity assessment of dicationic versus monocationic ionic liquids as a more environmentally friendly alternative. Ecotoxicology and Environmental Safety, 150, 129-135. https://doi.org/10.1016/j.ecoenv.2017.11.073

Nicolaescu, P., Rosenstengel, M., Derntl, M., Klamma, R., \& Jarke, M. (2018). Near real-time collaborative modeling for view-based Web information systems engineering. Information Systems, 7491, 23-39. https://doi.org/10.1016/j.is.2017.07.008

Oviawe, J.I. (2017). Bridging Skill Gap to Meet Technical, Vocational Education and Training School-Workplace Collaboration in the 21st century. International Journal of Vocational Education and Training Research, 3(1), 7-14. https://doi.org/10.11648/j.ijvetr.20170301.12

Palgunadi, J., Indarto, A., Winoto, H., \& Kim, H.S. (2010). Application of ionic liquids for separation of propyne from propylene: solubility and selectivity studies. Jurnal Teknik Kimia Indonesia, 9(3), 106-111. https://doi.org/10.5614/jtki.2010.9.3.5

Raj, J.J., Magaret, S., Pranesh, M., Lethesh, K.C., Devi, W.C., \& Mutalib, M.I.A. (2019). Dual functionalized imidazolium ionic liquids as a green solvent for extractive desulfurization of fuel oil: Toxicology and mechanistic studies. Journal of Cleaner Production, 213, 989-998. https://doi.org/10.1016/j.jclepro.2018.12.207

Rusman, R. (2016). The Development of an E-Learning-Based Learning Service for MKDP Curriculum and Learning at the Indonesia University of Education. Journal of Education and Practice, 7(31), 83-87. https://doi.org/10.21744/irjeis.v3i2.410

Safitri, H., Hamidah, I., \& Setiawan, W. (2019). The preliminary study of learning interaction in physics concepts for developing e-learning to promote students' critical thinking. Journal of Physics: Conference Series, 1157, 032054. https://doi.org/10.1088/1742-6596/1157/3/032054

Sánchez-García I., Ureña-Molina, M. del P., López-Medina, I.M., \& Pancorbo-Hidalgo, P.L. (2019). Knowledge, skills and attitudes related to evidence-based practice among undergraduate nursing students: A survey at three universities in Colombia, Chile and Spain. Nurse Education in Practice, 39, 117-123. https://doi.org/10.1016/j.nepr.2019.08.009

Sekine, T. (2020). Empirical Verifications of Web-Learning Environment to Enhance Learning Effectiveness and Motivation in Mechanical Drawing. Journal of Technology and Science Education, 10(2), 179-189. https://doi.org/10.3926/jotse.856

Taher, M., Hamidah, I., \& Suwarma, I.R. (2017). Profile of Students’ Mental Model Change on Law Concepts Archimedes as Impact of Multi-Representation Approach. Journal of Physics: Conference Series, 895(1), 012101. https://doi.org/10.1088/1742-6596/895/1/012101

Thiagarajan, S. (1974). Instructional development for training teachers of exceptional children: A sourcebook. Journal of School Psychology. Available at: https://eric.ed.gov/?id=ED090725

Tong, D.H., Loc, N.P., Uyen, B.P., \& Cuong, P.H. (2020). Applying experiential learning to teaching the equation of a circle: A case study. European Journal of Educational Research, 8(4), 239-255.

Valenzuela, B.D., Fragoso, O.G., Santaolaya, R., \& Munoz, J. (2017). Educational resources as learning Web services, an alternative point of view to learning objects. IEEE Latin America Transactions, 15(4), 711-719. https://doi.org/10.1109/TLA.2017.7896399

Vekariya, R.L. (2017). A review of ionic liquids: Applications towards catalytic organic transformations. Journal of Molecular Liquids, 227, 44-60. https://doi.org/10.1016/j.molliq.2016.11.123 
Wang, Y.L., Sarman, S., Laaksonen, A., Golets, M., Mocci, F., \& Lu, Z.Y. (2019). Multigranular modeling of ionic liquids: A book chapter in Ionic Liquids. Available at: https://arxiv.org/abs/1905.11145

Yulianti, I., Hamidah, I., \& Komaro, M. (2020). Green Chemistry principle: Ionic Liquids as a material teaching for vocational students. IOP Conference Series: Materials Science and Engineering, 850, 012047. https://doi.org/10.1088/1757-899X/850/1/012047

Zakiya, H. Sinaga, P., \& Hamidah, I. (2017). The effectiveness of multi modal representation textbooks to improve student's scientific literacy of senior high school students. AIP Conference Proceedings, 1848(1), 1-6. https://doi.org/10.1063/1.4983957

Published by OmniaScience (www.omniascience.com)

Journal of Technology and Science Education, 2021 (www.jotse.org)

\section{(c) (1) (8)}

Article's contents are provided on an Attribution-Non Commercial 4.0 Creative commons International License. Readers are allowed to copy, distribute and communicate article's contents, provided the author's and JOTSE journal's names are included. It must not be used for commercial purposes. To see the complete licence contents, please visit https://creativecommons.org/licenses/by-nc/4.0/. 